Article

\title{
Empirical Absolute Calibration Model for Multiple Pseudo-Invariant Calibration Sites
}

\author{
Bipin Raut ${ }^{1,2, *(\mathbb{0})}$, Morakot Kaewmanee ${ }^{2}$, Amit Angal ${ }^{3}{ }^{-}$, Xiaoxiong Xiong ${ }^{4}$ and Dennis Helder ${ }^{1}$ \\ 1 Department of Electrical Engineering and Computer Science, South Dakota State University (SDSU), \\ Brookings, SD 57007, USA; dennis.helder@sdstate.edu \\ 2 Image Processing Lab, Engineering Office of Research, South Dakota State University (SDSU), \\ Brookings, SD 57007, USA; morakot.kaewmanee@sdstate.edu \\ 3 Science Systems and Applications Inc., 10210 Greenbelt Road, Lanham, MD 20706, USA; \\ amit.angal@ssaihq.com \\ 4 Sciences and Exploration Directorate, NASA Goddard Space Flight Center, Greenbelt, MD 20771, USA; \\ xiaoxiong.xiong-1@nasa.gov \\ * Correspondence: bipin.raut@jacks.sdstate.edu; Tel.: +01-605-592-0046
}

Received: 3 April 2019; Accepted: 7 May 2019; Published: 9 May 2019

\begin{abstract}
This work extends an empirical absolute calibration model initially developed for the Libya 4 Pseudo-Invariant Calibration Site (PICS) to five additional Saharan Desert PICS (Egypt 1, Libya 1, Niger 1, Niger 2, and Sudan 1), and demonstrates the efficacy of the resulting models at predicting sensor top-of-atmosphere (TOA) reflectance. It attempts to generate absolute calibration models for these PICS that have an accuracy and precision comparable to or better than the current Libya 4 model, with the intent of providing additional opportunities for sensor calibration. In addition, this work attempts to validate the general applicability of the model to other sites. The method uses Terra Moderate Resolution Imaging Spectroradiometer (MODIS) as the reference radiometer and Earth Observing-1 (EO-1) Hyperion image data to provide a representative hyperspectral reflectance profile of the PICS. Data from a region of interest (ROI) in an "optimal region" of 3\% temporal, spatial, and spectral stability within the PICS are used for developing the model. The developed models were used to simulate observations of the Landsat 7 (L7) Enhanced Thematic Mapper Plus (ETM+), Landsat 8 (L8) Operational Land Imager (OLI), Sentinel 2A (S2A) MultiSpectral Instrument (MSI) and Sentinel 2B (S2B) MultiSpectral Instrument (MSI) from their respective launch date through 2018. The models developed for the Egypt 1, Libya 1 and Sudan 1 PICS have an estimated accuracy of approximately $3 \%$ and precision of approximately $2 \%$ for the sensors used in the study, comparable to the current Libya 4 model. The models developed for the Niger 1 and Niger 2 sites are significantly less accurate with similar precision.
\end{abstract}

Keywords: Radiometric Calibration; Absolute Calibration; Empirical Model; EO-1 Hyperion; MODIS; PICS; Landsat; Sentinel; BRDF

\section{Introduction}

Continuous post-launch radiometric calibration of satellite-based Earth imaging sensors is required to confirm the accuracy of their image products and monitor their radiometric response over time. This calibration can be performed through the use of onboard calibration sources, such as lamps or solar diffuser panels if they are present; however, they can significantly increase the cost of sensor design and operation. Alternatively, calibration can be performed using image data acquired from PICS, which are regions on the Earth's surface exhibiting minimal change over long periods. To date, the use of these sites has been primarily limited to cross-calibration and sensor stability monitoring. 


\subsection{PICS Radiometric Stability}

PICS-based assessment of sensor radiometric stability has been used for more than two decades. Early research by Cosnefroy et al. identified 20 sites with $3 \%$ or better spatial uniformity and $1 \%$ to $2 \%$ temporal variability; many of these sites were located throughout North Africa in the Sahara Desert [1]. The Committee on Earth Observation Satellites (CEOS) endorsed six of these North African PICS exhibiting $3 \%$ or less variability (Libya 4, Mauritania 1, Mauritania 2, Algeria 3, Libya 1, and Algpt (Egypt 1 and Egypt 2), reporting a 3\% or less temporal variability across all bands. Helder's analysis ieria 5) as standard "reference" sites to be used for long-term radiometric stability monitoring [2]. In 2010, Helder et al. developed an algorithm for locating optimal sites which are temporally stable [3]. The algorithm included Libya 4, Libya 1, and Algeria 3 from the CEOS list, and identified new sites in Egydentified Libya 4 as the most temporally stable of the Sahara Desert PICS [3]. In 2012, the South Dakota State University Image Processing Laboratory (SDSU IPLAB) performed a stability analysis of several African PICS, including some of the PICS endorsed by CEOS; these PICS were ranked, by the spectral band wavelength, in order of increasing temporal uncertainty (with lower temporal uncertainty resulting in a higher ranking). The results of this analysis supported Helder's result and ranked Libya 4, Niger 1, Sudan 1, Niger 2, Egypt 1 and Libya 1 as the top stable sites with respect to temporal uncertainty [4]. As one of the most temporally stable sites, Libya 4 has been extensively used in radiometric calibration work [4-8].

In 2016, the SDSU IPLAB developed a PICS normalization algorithm to combine image data from multiple PICS into a single dataset with increased temporal resolution. The process identified "optimal" regions exhibiting 3\% or less temporal, spatial, and spectral variability [9]. The algorithm was applied to Egypt 1, Libya 1, Libya 4, Niger 1, Niger 2 and Sudan 1 to overcome limitations in data quantity. Optimal regions identified within these PICS were shown to be spatially, temporally and spectrally stable to within $3 \%$ accuracy, similar to Libya 4 [9].

\subsection{PICS for Absolute Radiometric Calibration}

PICS have demonstrated excellent potential for use in absolute calibration [4,8,10-13]. Establishing PICS as an absolute calibration data source with SI traceability would allow multiple sensors to measure radiance/reflectance of a PICS at the same radiometric scale without requiring analysis of coincident/near coincident image pairs. In 2004, Govaerts et al. investigated the development of an absolute calibration model using PICS for geostationary satellite sensors [11]; in 2012, the initial model was extended with an advanced radiative transfer model accounting for polarization effects and non-spherical aerosol models to better characterize the atmospheric effects. This work reported a prediction accuracy within 3\% for Libya 4 based on observations from the PARASOL, MERIS, AATSR, Aqua MODIS, and VEGETATION 2 sensors [12].

In 2012, Helder et al. investigated the concept of an empirical absolute calibration model using PICS. Terra MODIS was used as a reference radiometer. The spectral profile for each PICS was extracted from EO-1 Hyperion hyperspectral images of Libya 4. The developed model was validated with L7 ETM+ image data. The model showed accuracy within 3\% in the visible and $6 \%$ in the short wave infrared (SWIR) region [10].

In 2013, Bhatt et al. developed a desert daily exoatmospheric radiance model (DERM) based on a well-calibrated geostationary Earth orbit (GEO) sensor. The DERM was based on daily radiance observed over Libya 4. The model was used to transfer the calibration to GEO sensors located in the same equatorial longitudinal location. Scanning Image Absorption Spectrometer for Atmospheric Cartography (SCIAMACHY) hyperspectral radiance data was used to account for spectral response function differences between the calibrated and uncalibrated sensors. The reference Meteosat-9 DERM was consistent within $0.4 \%$ and $1.9 \%$ for Meteosat- 8 and Meteosat -7 , respectively. Moreover, GOES-11 DERM was consistent to $1 \%$ and 3\%, respectively, with GOES-10 and GOES-15 [8]. 
In 2014, Mishra et al. extended Helder's model by including the view zenith angle in the bidirectional reflectance distribution function (BRDF) model [4]. The model predicted TOA reflectance over Libya 4 with a $3 \%$ accuracy and random error within $2 \%$ across all bands [4].

\subsection{Objectives of This Work}

This article describes the extension of Mishra's empirical calibration model to the remaining PICS studied by the SDSU IPLAB (Egypt 1, Libya 1, Niger 1, Niger 2 and Sudan 1). Unlike Mishra's development, the proposed models are developed based on "optimal" regions of the PICS exhibiting $3 \%$ or less temporal, spatial, and spectral stability. Validation of the developed models follows Mishra's general approach.

This article is organized as follows. Section 1 provides a brief overview of the topic relating to PICS usage and initial efforts at developing PICS-based absolute calibration. Section 2 discusses the methodology used to develop the proposed absolute calibration models. Section 3 presents the model development and validation results for each site. Finally, Section 4 summarizes the article and provides potential directions for future work in this area.

\section{Materials and Methods}

\subsection{Sensor Overview}

\subsubsection{MODIS}

Terra MODIS is one of the key instruments for the National Aeronautics and Space Administration (NASA) Earth Observing System (EOS) that has operated more than 19 years. It was launched on 18 December 1999. MODIS observes the Earth's surface in 36 spectral bands that include the visible / near-infrared spectrum from $0.412 \mu \mathrm{m}$ to $2.1 \mu \mathrm{m}$, at spatial resolutions of $250 \mathrm{~m}$ in the shorter wavelength bands and $500 \mathrm{~m}$ in the longer wavelength bands. It typically observes with swaths of approximately $2330 \mathrm{~km}$ in length, allowing for 2-day global coverage at the Equator [14]. As a result, MODIS has generated an unprecedented amount of data openly available to the science community.

Regular and extensive testing and calibration has been carried out on the instrument to characterize its performance. Pre-launch calibration was performed using a spherical integrating source (SIS-100) traceable to the National Institute of Standards and Technology (NIST) standards [15]. In orbit, the reflective solar bands are calibrated using the onboard solar diffuser (SD) and a Solar Diffuser Stability Monitor (SDSM). An onboard spectroradiometric calibration assembly is used to evaluate and monitor overall spatial and spectral performance, and lunar observations are used to track calibration stability $[15,16]$. SD/SDSM calibrations are performed on a regular basis, resulting calibration data are updated to the Level 1B (L1B) product generation code as necessary [14]. Sensor on-orbit performance is regularly assessed, leading to continuous improvement of the processing algorithms used to generate high-level science products. With respect to the reflective bands, Terra MODIS is generally viewed as one of the best-calibrated sensors, due to this effort; the reported radiometric calibration uncertainties of the MODIS TOA reflectance products are approximately $2 \%$ for sensor zenith angles up to $\pm 45^{\circ}$ [15].

\subsubsection{EO-1 Hyperion Imaging Spectrometer}

EO-1 was launched on 21 November 2000, as part of NASA's New Millennium Program (NMP) intended to provide high-quality calibrated hyperspectral data [17]. Hyperion imaged the Earth's surface in 196 bands ranging from $0.4 \mu \mathrm{m}$ to $2.5 \mu \mathrm{m}$, at a spectral resolution of $10 \mathrm{~nm}$ and spatial resolution of $30 \mathrm{~m}$. Hyperion was capable of imaging up to $\pm 25^{\circ}$ off its typical nadir orientation. On-orbit calibration of Hyperion was performed using the onboard solar diffuser and lamp sources, lunar observations, and vicarious measurements of selected targets [18].

Between 2006 and 2007, a series of de-orbiting maneuvers were performed in order to lower EO-1's altitude from approximately $705 \mathrm{~km}$ to approximately $690 \mathrm{~km}$, so as to maintain a local equatorial 
crossing time of 10:00 AM [19]. After late 2011, EO-1 began shifting to an earlier equatorial crossing time as its initial fuel supply was exhausted, which ultimately resulted in its official decommissioning in early 2017. McCorkel et al. and Campbell et al. have reported reflectance-based calibrations repeatable to $2 \%$, with an approximate $3 \%$ to $5 \%$ accuracy level, using image data acquired prior to $2012[20,21]$.

\subsection{Data Preprocessing}

The MODIS Characterization Support Team (MCST) provided Terra MODIS Collection 6.1 image data products for each PICS. The corresponding cloud-free L7 ETM+, L8 OLI, S2A MSI, S2B MSI and EO-1 Hyperion image data for the selected PICS were retrieved from the existing SDSU IPLAB archive. These datasets had previously been downloaded through the United States Geological Survey (USGS) Earth Explorer (https://earthexplorer.usgs.gov/) as Level 1T (L1T) products with radiometric and precision geometric corrections applied. The MODIS image data products were already processed to TOA reflectance; the L7 ETM+, L8 OLI, S2A MSI, S2B MSI and EO-1 Hyperion image data were converted to TOA reflectance using the conversion coefficients specified in the associated product metadata. It should be noted that the S2A MSI image data were processed to different processing levels, as indicated in the corresponding metadata; previously generated image data were not updated to the most current processing level.

\subsection{Calibration Sites and ROI}

The five PICS investigated in this work (Egypt 1, Sudan 1, Libya 1, Niger 1 and Niger 2) are located in the Sahara Desert of North Africa. They are currently used for sensor stability monitoring and radiometric cross-calibration purposes by the SDSU IPLAB [9,22]. They exhibit relatively high surface reflectance with low aerosol loading, good temporal stability, and minimal vegetation cover.

The SDSU IPLAB's PICS normalization process (PNP) algorithm was applied to the OLI image data from each site to identify "optimal" regions exhibiting 3\% or less temporal, spatial, and spectral variability [9]. Figure 1a-e show the optimal regions (white pixels) identified for each site, as well as fixed ROIs (red rectangles). These fixed ROIs were used to evaluate the PNP method's performance and defines sub-regions with maximum possible area fitting completely within the optimal regions. The figures also show the corresponding Hyperion images that intersect the optimal region. For the Libya 1 and Niger 2 PICS, the Hyperion images also intersected with the fixed optimal region ROI. Table 1 provides the corner lat/lon coordinates of the fixed optimal region and the associated Worldwide Reference System-2 (WRS-2) path and row.

Table 1. Fixed optimal region ROI latitude and longitude coordinates.

\begin{tabular}{cccccc}
\hline PICS & $\begin{array}{c}\text { WRS-2 } \\
\text { Path/Row }\end{array}$ & $\begin{array}{c}\text { Upper Left } \\
\text { Latitude }\end{array}$ & $\begin{array}{c}\text { Upper Left } \\
\text { Longitude }\end{array}$ & $\begin{array}{c}\text { Lower Right } \\
\text { Latitude }\end{array}$ & $\begin{array}{c}\text { Lower Right } \\
\text { Longitude }\end{array}$ \\
\hline Egypt 1 & $179 / 41$ & $27.68^{\circ}$ & $26.26^{\circ}$ & $27.16^{\circ}$ & $26.50^{\circ}$ \\
Libya 1 & $187 / 43$ & $24.86^{\circ}$ & $13.32^{\circ}$ & $24.56^{\circ}$ & $13.67^{\circ}$ \\
Niger 1 & $189 / 46$ & $20.54^{\circ}$ & $9.20^{\circ}$ & $20.28^{\circ}$ & $9.53^{\circ}$ \\
Niger 2 & $188 / 45$ & $21.48^{\circ}$ & $10.39^{\circ}$ & $21.25^{\circ}$ & $10.71^{\circ}$ \\
Sudan1 & $177 / 45$ & $21.76^{\circ}$ & $27.60^{\circ}$ & $21.41^{\circ}$ & $27.81^{\circ}$ \\
\hline
\end{tabular}

\subsection{BRDF Model}

Due to variations in solar and sensor position, a sensor will likely measure significantly different TOA reflectance of a specific target each time that it is imaged. This effect is represented by the BRDF. To obtain consistently reliable TOA reflectance measurements for an individual sensor and compare reflectance measurements between multiple sensors, BRDF correction should be applied to the image data. The correction process typically involves application of a convolution kernel whose coefficients are generated from a BRDF model derived from physical considerations of the surface (i.e., composition, 
particle shape, etc.) [23], empirical analyses of specific image data considering the available solar and sensor geometry information $[4,10]$, or a semi-empirical approach combining physical and empirical approaches [24,25]. At SDSU IPLAB, a laboratory experiment was performed on desert sample sand to measure the surface reflectance characteristics. The experiment exhibited a linear and quadratic relationship of reflectance with solar and view zenith angle respectively [26]. The following sections describe the procedure used to generate the appropriate BRDF models for each sensor.

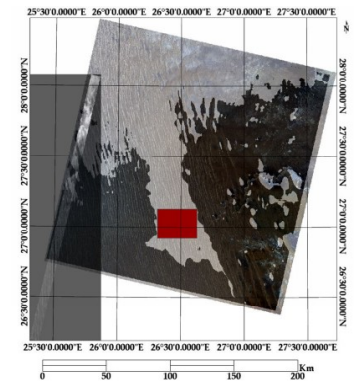

(a)

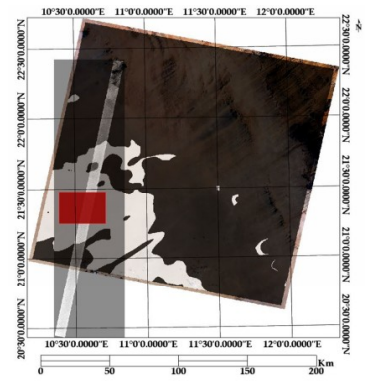

(d)

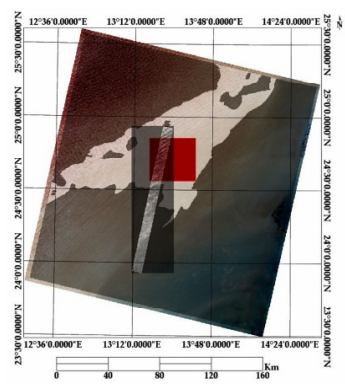

(b)

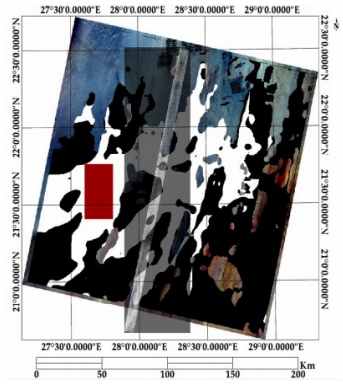

(e)

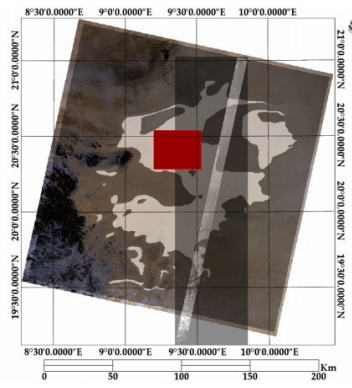

(c)

Figure 1. South Dakota State University (SDSU) identified standard region of interest (ROI) and optimal region of Pseudo-Invariant Calibration Site (PICS); (a) Egypt $1\left(27.41^{\circ} \mathrm{N}, 26.38^{\circ}\right)$; (b) Libya $1\left(24.70^{\circ} \mathrm{N}\right.$, $\left.13.49^{\circ} \mathrm{E}\right)$; (c) Niger $1\left(9.36^{\circ} \mathrm{N}, 20.41^{\circ} \mathrm{E}\right)$; (d) Niger $2\left(10.44^{\circ} \mathrm{N}, 20.8^{\circ} \mathrm{E}\right)$; (e) Sudan $1\left(21.40^{\circ} \mathrm{N}, 27.70^{\circ} \mathrm{E}\right)$.

\subsubsection{MODIS Solar Zenith BRDF Model}

Image data acquired prior to 2017 with sensor zenith angles within $\pm 7.50^{\circ}$ of nadir were used to generate linear models based on solar zenith angle, as shown in Figure 2 for the near infrared (NIR) band. The resulting slope and intercept coefficients from the fits were then plotted as functions of each MODIS band's center wavelength, and additional curves were fitted to that data in order to generate a slope and an intercept prediction model applicable to the Hyperion data. Figure 3 shows the resulting curve fits of the linear slope for Egypt 1; the low root-mean-square error (RMSE) and high adjusted $\mathrm{R}^{2}$ value suggest the model fits the data well. Table 2 summarizes the best slope and intercept hyperspectral model fits obtained for each PICS.

The developed BRDF models are purely empirical in nature (i.e., they are based only on the observed TOA reflectances derived from the image data). Following Mishra's approach, exponential curves were initially fit to the estimated BRDF model coefficients; quadratic and cubic fits were then considered when an exponential fit exhibited an adjusted $\mathrm{R}^{2}$ value of less than $90 \%$. A low adjusted $\mathrm{R}^{2}$ value was obtained through an exponential model fit for Libya 1, Niger 1 and Niger 2. For Niger 1 and Niger 2, only a cubic model fit satisfied the required $\mathrm{R}^{2}$ threshold. This dissimilarity in applicable models may be accounted by differences in the physical structure and/or intrinsic surface properties for each PICS. 


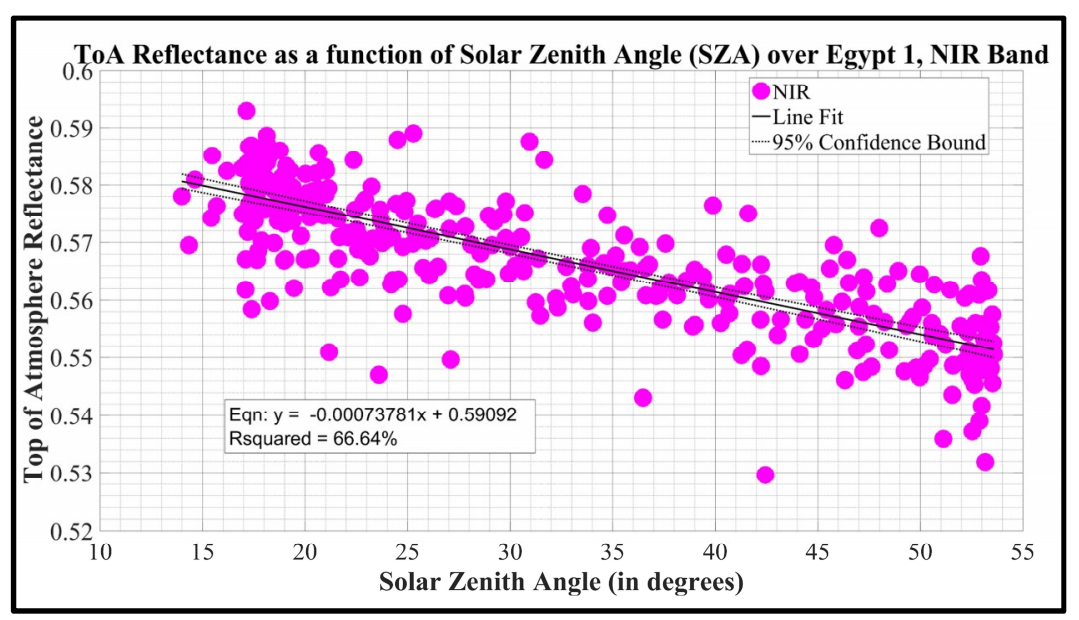

Figure 2. Simple Linear bidirectional reflectance distribution function (BRDF) correction model of Egypt 1 based on solar zenith angle.

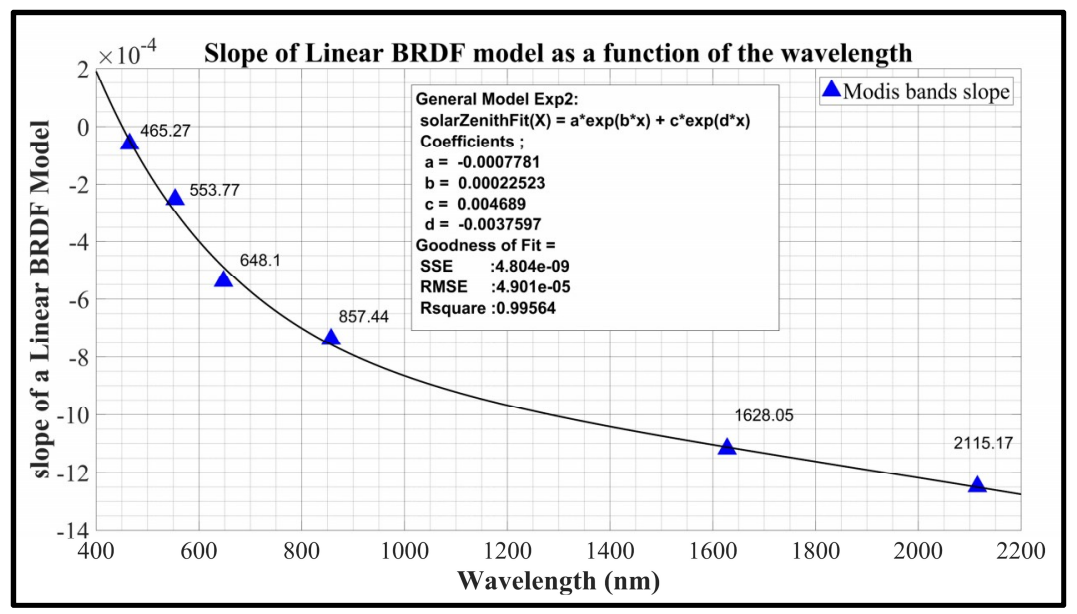

Figure 3. MODIS Solar Zenith Angle Slope Prediction Model as a function of wavelength.

Table 2. Hyperspectral model of BRDF slope and intercept as functions of solar zenith angle.

\begin{tabular}{ccccc}
\hline PICS & $\begin{array}{c}\text { Number } \\
\text { of Scenes }\end{array}$ & $\begin{array}{c}\text { Solar Zenith Angle } \\
\text { Variation (degree) }\end{array}$ & Slope Model Fit & Intercept Model Fit \\
\hline Egypt 1 & 330 & $13-53$ & Two-piece Exponential & Two-piece Exponential \\
Libya 1 & 347 & $13-51$ & Quadratic & Two-piece Exponential \\
Niger 1 & 318 & $15-46$ & Cubic & Two-piece Exponential \\
Niger 2 & 269 & $14-49$ & Cubic & Two-piece Exponential \\
Sudan 1 & 258 & $13-50$ & Two-piece Exponential & Two-piece Exponential \\
\hline
\end{tabular}

\subsubsection{Hyperion View Zenith BRDF Model}

For each PICS, representative hyperspectral profiles were derived from rectangular ROIs in the Hyperion image data. These ROIs were located within the "optimal" $3 \%$ temporal, spectral, and spatial stability region previously mapped in the corresponding OLI image data. For Egypt 1, Niger 1, and Sudan 1, Hyperion data prior to 2012 were considered for model development due to changes in the mean local equatorial crossing time after 2012. For Libya 1 and Niger 2, Hyperion image data were only acquired after 2012, so these data were used to develop the model.

The slope models developed in Section 2.4.1 were used to normalize the Hyperion image data to a reference $30^{\circ}$ solar zenith angle. The $30^{\circ}$ reference angle provided approximate symmetric division of solar zenith angle. Eight high-transmittance Hyperion bands roughly corresponding to the MODIS 
band center wavelengths $(467.5 \mathrm{~nm}, 559.14 \mathrm{~nm}, 671 \mathrm{~nm}, 864.4 \mathrm{~nm}, 1023.4 \mathrm{~nm}, 1235 \mathrm{~nm}, 1628 \mathrm{~nm}$, and $2143 \mathrm{~nm}$ ) were then used to develop quadratic BRDF models based on view zenith angle. These selected bands are different than that are used in Optical Sensor Calibration with simulated Radiance (OSCAR) approach [12]. Figure 4 shows the resulting model fit for the $467.5 \mathrm{~nm}$ band of Egypt 1 . For Egypt 1, the image acquisitions were "one-sided", i.e., the view zenith angle was always in the same direction with respect to nadir; to facilitate their analysis estimates of view zenith angle in the opposite direction from nadir were extrapolated from the available zenith angles assuming a quadratic function. This extrapolation might add some uncertainty to the Egypt 1 model reflectance prediction in the opposite direction from nadir. As with the solar zenith regression coefficients, the coefficients from the view zenith angle fits were plotted as a function of wavelength and then fitted with exponential, quadratic or cubic curves to generate the coefficient prediction models. However, the adjusted $\mathrm{R}^{2}$ threshold was relaxed to $80 \%$ for the view zenith angle model, as the BRDF effects tend to be less pronounced than for the solar zenith angle. The curve which satisfied the threshold of $80 \%$ was selected as curve fit for calculated slopes. Figures 5 and 6 show the resulting linear and quadratic coefficient fits, respectively, for Egypt 1. Table 3 summarizes, for each PICS, the polynomial curve fit of the linear and quadratic coefficients having the lowest RMSE that still satisfies the selected $\mathrm{R}^{2}$ thresholds.

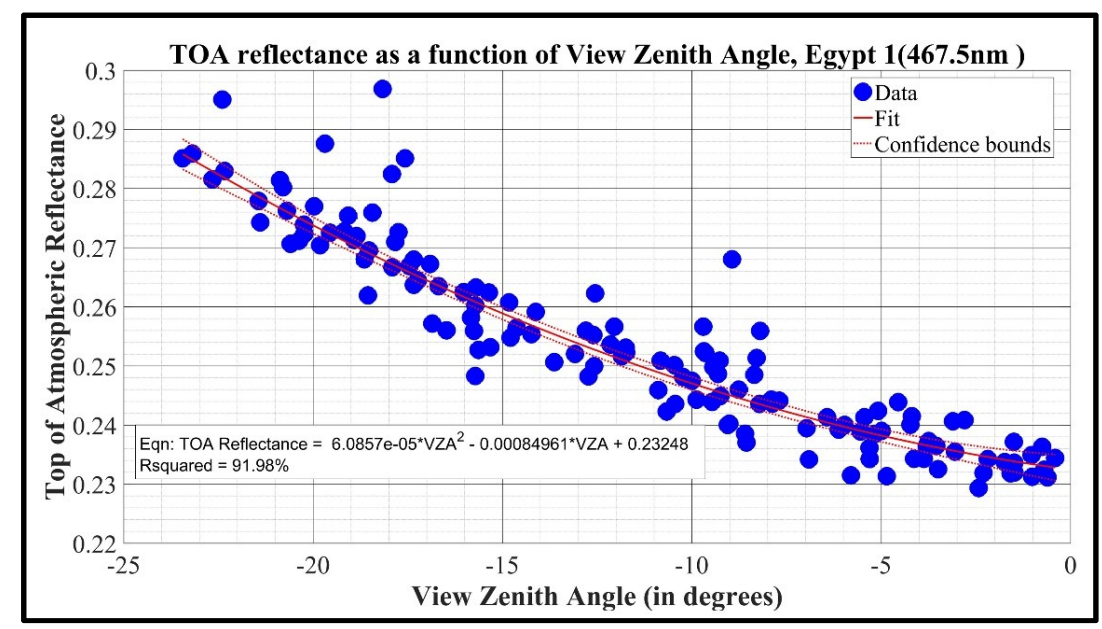

Figure 4. Quadratic BRDF correction Model of Egypt 1 based on view zenith angle.

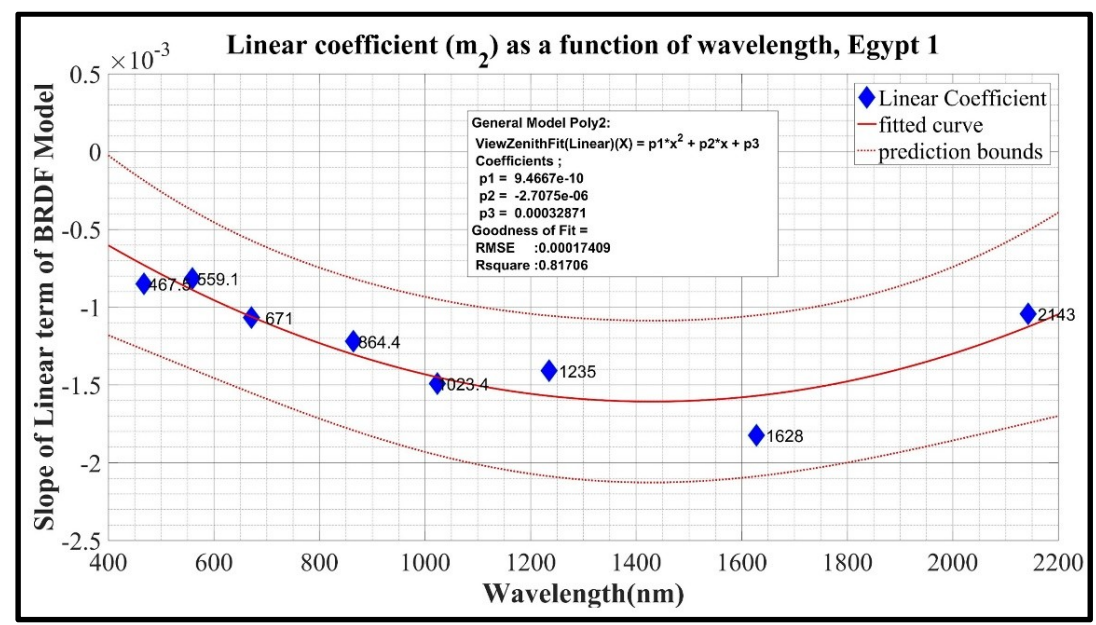

Figure 5. Quadratic model fit on linear coefficient as a function of wavelength for Egypt 1. 


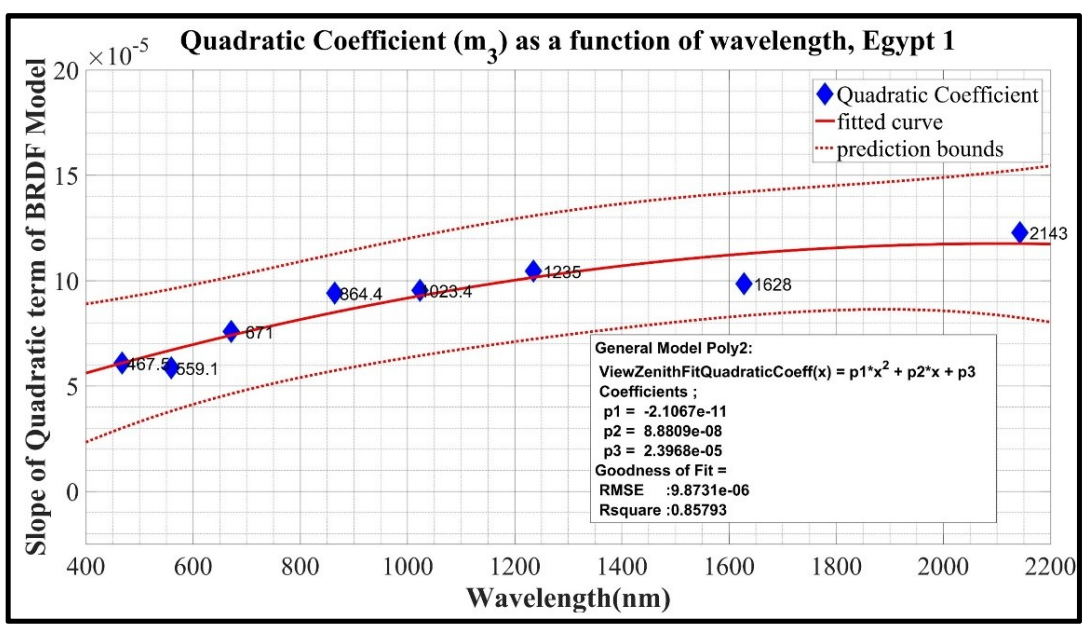

Figure 6. Quadratic model fit on quadratic coefficient as a function of wavelength for Egypt 1.

Table 3. Summary of line fit for calculated slope of first order and second term as a function of wavelength for five PICS.

\begin{tabular}{cccc}
\hline Sites & $\begin{array}{c}\text { Number of } \\
\text { Scenes }\end{array}$ & $\begin{array}{c}\text { Model Fit for First order Term } \\
\left(\mathbf{m}_{\mathbf{1}}\right)\end{array}$ & $\begin{array}{c}\text { Model Fit for Second order Term } \\
\left(\mathbf{m}_{\mathbf{2}}\right)\end{array}$ \\
\hline Egypt 1 & 135 & Quadratic & Quadratic \\
Libya 1 & 73 & Cubic & Cubic \\
Niger 1 & 30 & Cubic & Cubic \\
Niger 2 & 5 & Cubic & Cubic \\
Sudan 1 & 112 & Cubic & Cubic \\
\hline
\end{tabular}

\subsection{Scaling Hyperion to Terra MODIS}

Scale factors to match the Hyperion data to the six MODIS solar reflective bands were determined as follows:

$$
\begin{gathered}
\mathrm{k}=\frac{\rho_{\text {MODIS }}}{\rho_{\text {BandedHyperion }}} \\
\rho_{\text {BandedHyperion }}=\frac{\int \rho_{\mathrm{h}} \times \mathrm{RSR}_{\text {MODIS }}}{\int \mathrm{RSR}_{\text {MODIS }}}
\end{gathered}
$$

$\rho_{\text {MODIS }}$ is the TOA reflectance determined from a set of MODIS and Hyperion near-coincident image pairs. $\rho_{\text {BandedHyperion }}$ is the TOA reflectance from the near-coincident pair set that is "banded" with the MODIS relative spectral response (RSR). The "banded" TOA reflectance is calculated by integrating the RSR of the sensor with the Hyperion profile at each sampled wavelength, weighted by the respective RSR. Initially, near-coincident pairs 5 days apart with solar and view zenith angle differences within $\pm 5^{\circ}$ were considered. For Libya 1 and Niger 2, these criteria were relaxed to near-coincident pairs 8 days apart with solar and view zenith differences within $\pm 10^{\circ}$, since no coincident pairs were acquired over these sites. Table 4 gives the mean k-scale factors with standard deviation derived for five PICS calculated using MODIS and Hyperion near coincident pairs. For the remaining Hyperion bands, the scaling factors were determined as follows:

- For the range of Hyperion bands corresponding to the Red (590 nm-835 nm), NIR ( $835 \mathrm{~nm}-960 \mathrm{~nm})$, SWIR-1 (960 nm-1853 nm), and SWIR-2 (1850 nm-2395 nm) bands were set to the calculated $\mathrm{k}$-scale value, as these bands show no apparent linear variation.

- For the range of Hyperion bands corresponding to the Blue (440 nm-475 nm) and Green $(475 \mathrm{~nm}-590 \mathrm{~nm})$ bands, the k-scale factors were determined through the ratio of piecewise linearly interpolated MODIS Blue and Green band data to the Hyperion bands, as there appears to be a monotonic trend to the Hyperion Blue and Green band reflectance. 
- For the range of Hyperion bands corresponding to the Coastal/Aerosol (CA) band (400 nm-440 nm), the initial k-scale factor for the Blue band range was used, as the MODIS band covering this spectral region, band $9(443 \mathrm{~nm})$ is an high-gain ocean band and experiences saturation while viewing the desert targets.

Table 4. Mean k-scale Factors derived from MODIS/Hyperion near coincident pairs.

\begin{tabular}{cccccc}
\hline Bands/PICS & Egypt 1 & Libya 1 & Niger 1 & Niger 2 & Sudan 1 \\
\hline Blue $(465.27 \mathrm{~nm})$ & $1.016 \pm 0.03$ & $0.989 \pm 0.03$ & $1.007 \pm 0.02$ & $0.995 \pm 0.08$ & $0.987 \pm 0.03$ \\
Green $(553.77 \mathrm{~nm})$ & $1.050 \pm 0.03$ & $1.024 \pm 0.03$ & $1.062 \pm 0.01$ & $1.023 \pm 0.03$ & $1.011 \pm 0.04$ \\
Red & $1.029 \pm 0.02$ & $1.000 \pm 0.02$ & $1.025 \pm 0.01$ & $1.023 \pm 0.00$ & $0.982 \pm 0.03$ \\
$(648.1 \mathrm{~nm})$ & & & & \\
NIR $(857.44 \mathrm{~nm})$ & $1.013 \pm 0.02$ & $0.988 \pm 0.01$ & $0.999 \pm 0.03$ & $1.007 \pm 0.01$ & $0.963 \pm 0.03$ \\
SWIR-1 $(1628.05 \mathrm{~nm})$ & $0.978 \pm 0.01$ & $0.948 \pm 0.01$ & $0.949 \pm 0.01$ & $0.950 \pm 0.03$ & $0.935 \pm 0.02$ \\
SWIR-2 $(2115.12 \mathrm{~nm})$ & $0.925 \pm 0.01$ & $0.902 \pm 0.02$ & $0.918 \pm 0.01$ & $0.924 \pm 0.07$ & $0.890 \pm 0.03$ \\
\hline
\end{tabular}

\subsection{Absolute Calibration Model}

The final absolute calibration model used in this work follows [4]:

$$
\hat{\rho}_{\mathrm{PICS}}(\lambda, \mathrm{SZA}, \mathrm{VZA})=\frac{\mathrm{k}(\lambda) \times \rho_{\mathrm{h}}(\lambda)}{1-\left(\mathrm{SZA}-30^{\circ}\right) \times \mathrm{m}_{1}(\lambda)-\operatorname{VZA}(\lambda) \times \mathrm{m}_{2}(\lambda)-\mathrm{VZA}^{2} \times \mathrm{m}_{3}(\lambda)}
$$

Here, $\rho_{h}(\lambda)$ is the mean near-coincident Hyperion TOA reflectance for the selected PICS. $\mathrm{k}(\lambda)$ is the k scaling factor normalizing the Hyperion spectrum $\rho_{h}(\lambda)$ to MODIS. SZA is the solar zenith angle for the selected sensor on the image acquisition date. VZA is the view zenith angle for the selected sensor on the image acquisition date. $\mathrm{m}_{1}$ is the slope coefficient of the BRDF model for solar zenith angle correction, as described in Section 2.4.1. $\mathrm{m}_{2}$ and $\mathrm{m}_{3}$ are the linear and quadratic coefficients of the BRDF model for view zenith angle correction, as described in Section 2.4.2. The model presented in Equation (3) does not include an atmospheric parameter as in Mishra's model. Barsi et al. showed using image data with accurate pixel-based angle information renders the effect of the atmospheric model on the absolute calibration model negligible [27]. Absolute calibration model developed without atmospheric model has shown equivalent accuracy and precision level as Mishra's absolute calibration model [28].

As implemented for this work, the model generates three metrics that can be used for its assessment: (1) an accuracy estimated as the ratio between the RMSEs of the model-predicted and observed TOA reflectances to the mean value of the observed TOA reflectance; (2) a percentage difference, calculated as the ratio of the model-predicted and observed reflectance differences to the model-predicted TOA reflectance; and (3) a precision estimated as the standard deviation of the model-predicted and observed TOA reflectance differences, also expressed as a percentage.

$$
\begin{gathered}
\text { RMSE }=\frac{\sqrt[2]{\operatorname{mean}\left(\left(\hat{\rho}_{\text {PICS }}(\lambda, \mathrm{SZA}, \mathrm{VZA})-\rho_{\text {measured }}\right)^{2}\right)}}{\operatorname{mean}\left(\rho_{\text {measured }}\right)} \times 100 \% \\
\text { TOA Reflectance Percentage Difference }=\left(\frac{\hat{\rho}_{\text {PICS }}(\lambda, \mathrm{SZA}, \mathrm{VZA})-\rho_{\text {measured }}}{\hat{\rho}_{\text {PICS }}(\lambda, \mathrm{SZA}, \mathrm{VZA})}\right) \times 100 \% \\
\text { Standard Deviation Percentage }(\mathrm{STD})=\left(\frac{\operatorname{std}\left(\hat{\rho}_{\text {PICS }}(\lambda, \mathrm{SZA}, \mathrm{VZA})-\rho_{\text {measured }}\right)}{\text { mean }\left(\rho_{\text {measured }}\right)}\right) \times 100 \%
\end{gathered}
$$

\subsection{Uncertainty}

Four primary sources of uncertainty for the absolute calibration model have been identified. These are: (1) uncertainty in the k-scale factor; (2) the spatial uncertainty in the PICS Hyperion 
spectra; (3) uncertainties in the calculation of the solar and view zenith angles SZA and VZA; and (4) uncertainties in the SZA and VZA correction coefficients $\mathrm{m}_{1}, \mathrm{~m}_{2}$, and $\mathrm{m}_{3}$.

Correlation between variables are fundamental for the uncertainty analysis. Nevertheless, accurate measurement of correlation depends on the size of sample data. A small sample data leads to false detection of correlation [29]. The model parameters such as k-scale factor, Hyperspectral spectrum and BRDF coefficients are derived from near-coincident pairs. Since, the number of acquired near-coincident pairs are less than or equal to 7 for all five PICS, there is high likelihood of detecting false correlation between the variables. Therefore, an assumption of no correlation between variables were assumed for uncertainty analysis. According to the International standards Organization Guide to the Expression of Uncertainty in Measurements (ISO-GUM) method [30], assuming the identified uncertainty sources are statistically independent, the final uncertainty of the model is given by:

$$
\begin{gathered}
\sigma_{\rho_{\mathrm{PICS}}}^{2}=\left(\frac{\partial \rho_{\mathrm{PICS}}}{\partial \mathrm{k}}\right)^{2} \times \sigma_{\mathrm{k}}^{2}+\left(\frac{\partial \rho_{\mathrm{PICS}}}{\partial \rho_{\mathrm{h}}}\right)^{2} \times \sigma_{\rho_{\mathrm{h}}}^{2}+\left(\frac{\partial \rho_{\mathrm{PICS}}}{\partial \mathrm{SZA}}\right)^{2} \times \sigma_{\mathrm{SZA}}^{2}+\left(\frac{\partial \rho_{\mathrm{PICS}}}{\partial \mathrm{VZA}}\right)^{2} \times \sigma_{\mathrm{VZA}}^{2} \\
+\left(\frac{\partial \rho_{\mathrm{PICS}}}{\partial \mathrm{m}_{1}}\right)^{2} \times \sigma_{\mathrm{m}_{1}}^{2}+\left(\frac{\partial \rho_{\mathrm{PICS}}}{\partial \mathrm{m}_{2}}\right)^{2} \times \sigma_{\mathrm{m}_{2}}^{2}+\left(\frac{\partial \rho_{\mathrm{PICS}}}{\partial \mathrm{m}_{3}}\right)^{2} \times \sigma_{\mathrm{m}_{3}}^{2}
\end{gathered}
$$

Section 3.3 summarizes the estimated overall uncertainties in the model as developed for each PICS.

\section{Results and Discussion}

\subsection{Validation with MODIS}

As described in Section 2, empirical absolute calibration models were developed for the five SDSU PICS using the "optimal region." Estimates for the accuracy and precision of the models were determined using the three-error measurement statistic tools defined in Section 2.6. Since the models are based on Terra MODIS and Hyperion measurements, an initial validation of the model was performed using MODIS data.

Figure 7 compares the model predicted and measured TOA reflectances in the MODIS NIR band (band 2) for Egypt 1. Figure 8 presents the corresponding accuracy and precision of model prediction. The RMSE (accuracy) between the model predictions and measurements is approximately $1.46 \%$, with a standard deviation (precision) of approximately $1.44 \%$; these are well within the $3 \%$ accuracy and $2 \%$ precision estimated for Libya 4 . Visually, the model predicted reflectances track the observed seasonal variation quite well. However, the model appears to predict lower reflectance levels as compared to the observed values. The mean absolute percentage error between the model and measurement is $1.17 \%$. Figure 8 gives the corresponding percentage difference between model prediction and measurement.

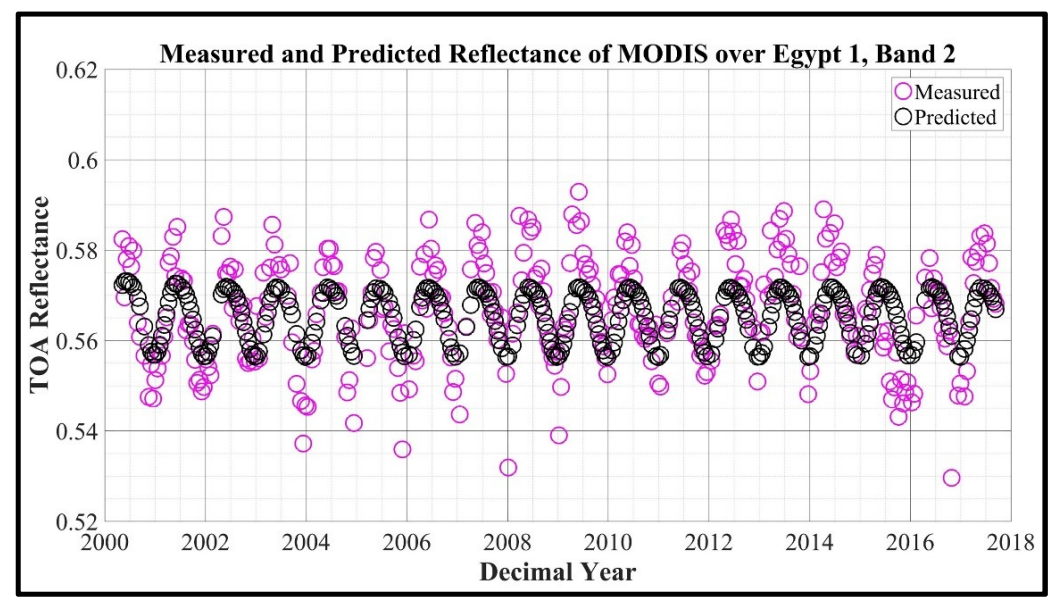

Figure 7. Terra MODIS observation of Egypt 1(magenta circle) NIR band and model prediction (black circle). 


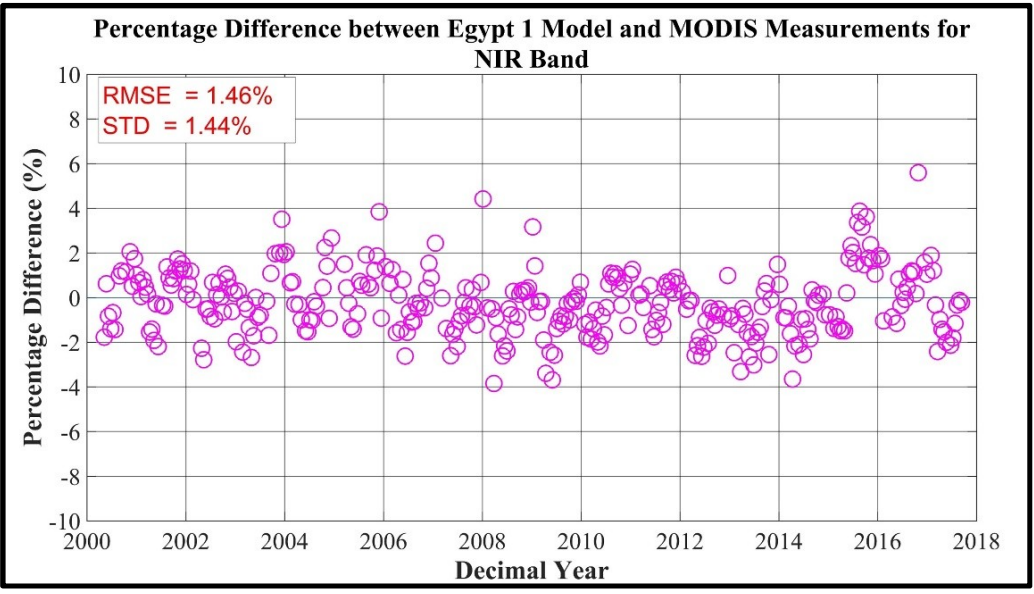

Figure 8. Comparison between Egypt 1 Model and MODIS Measurement (band 2).

Tables 5 and 6 summarizes the estimated accuracy and precision of the models, by band, for all of the SDSU PICS. In general, estimated accuracies are within 3\% for all bands, except for the Blue band of Libya 1 and SWIR bands for Niger 2. The Egypt 1, Niger 1 and Sudan 1 models show accuracy and precision within $2 \%$ which is very comparable to the accuracy and precision of Libya 4. With the exception of the Niger 2 models, the overall accuracies are well within the combined uncertainties of MODIS and Hyperion. Niger 2 was the least imaged PICS by Hyperion compared to the other PICS under study; only 5 cloud-free Hyperion acquisitions were available for model development. The scatter in residuals represented by standard deviation (STD) in Table 6 indicates how much of the model is yet to be explained. Instrument noise, instrument dark current fluctuations, site spatial heterogeneity, and the atmosphere are some possible contributors influencing scatter in the residuals $[10,13]$.

Table 5. Accuracy between model predictions and Terra MODIS observations.

\begin{tabular}{cccccc}
\hline Bands/PICS. & Egypt 1 (\%) & Libya 1 (\%) & Niger 1 (\%) & Niger 2 (\%) & Sudan 1 (\%) \\
\hline Blue & 2.64 & 3.13 & 2.38 & 2.74 & 2.09 \\
Green & 1.66 & 1.9 & 2.33 & 1.74 & 2.45 \\
Red & 1.68 & 2.44 & 2.94 & 1.83 & 1.66 \\
NIR & 1.58 & 2.23 & 2.79 & 2.20 & 1.63 \\
SWIR-1 & 2.04 & 2.93 & 1.26 & 5.25 & 1.55 \\
SWIR-2 & 2.89 & 2.56 & 2.38 & 7.87 & 1.97 \\
\hline
\end{tabular}

Table 6. Random uncertainties between model predictions and Terra MODIS observations.

\begin{tabular}{cccccc}
\hline Bands/PICS & Egypt 1 (\%) & Libya 1 (\%) & Niger 1 (\%) & Niger 2 (\%) & Sudan 1 (\%) \\
\hline Blue & 1.40 & 2.69 & 2.38 & 2.65 & 1.56 \\
Green & 1.48 & 1.59 & 1.12 & 1.73 & 1.12 \\
Red & 1.61 & 0.90 & 0.96 & 1.50 & 1.20 \\
NIR & 1.45 & 0.95 & 1.21 & 1.53 & 1.25 \\
SWIR-1 & 0.98 & 1.17 & 1.19 & 0.94 & 0.88 \\
SWIR-2 & 2.11 & 2.09 & 2.02 & 2.25 & 1.75 \\
\hline
\end{tabular}

\subsection{Validation of the Model with other Satellite Sensors}

Four sensors with well-understood calibrations (L7 ETM+, L8 OLI, S2A MSI, and S2B MSI) were selected to validate the model. Time series TOA reflectance datasets were constructed for each sensor, at each site, using the standard SDSU ROIs shown in Figure 1a-e.

Figure 9 compares the model-predicted (black asterisk) and measured (magenta circle) TOA reflectances in the ETM+ NIR band for Egypt 1. Significant scatter can be observed in the measured 
reflectances, possibly due to larger relative spectral response and inclusion of a water vapor absorption feature at $0.85 \mu \mathrm{m}$. The scatter is more apparent from the year 2017 onwards. Overall, the model consistently tracks the seasonal trend and predicts reflectance levels adequately. Figure 10 shows the corresponding percentage differences. The estimated accuracy of the model is approximately $1.99 \%$, well within the estimated 3\% accuracy for Libya 4 and the calibration uncertainties of the ETM+ and MODIS (approximately 5\% [31] and 2-3\% [15], respectively). The estimated precision is approximately $1.88 \%$; random variability of approximately $1-2 \%$ can be attributed primarily to site's spectral behavior and atmospheric differences [13].

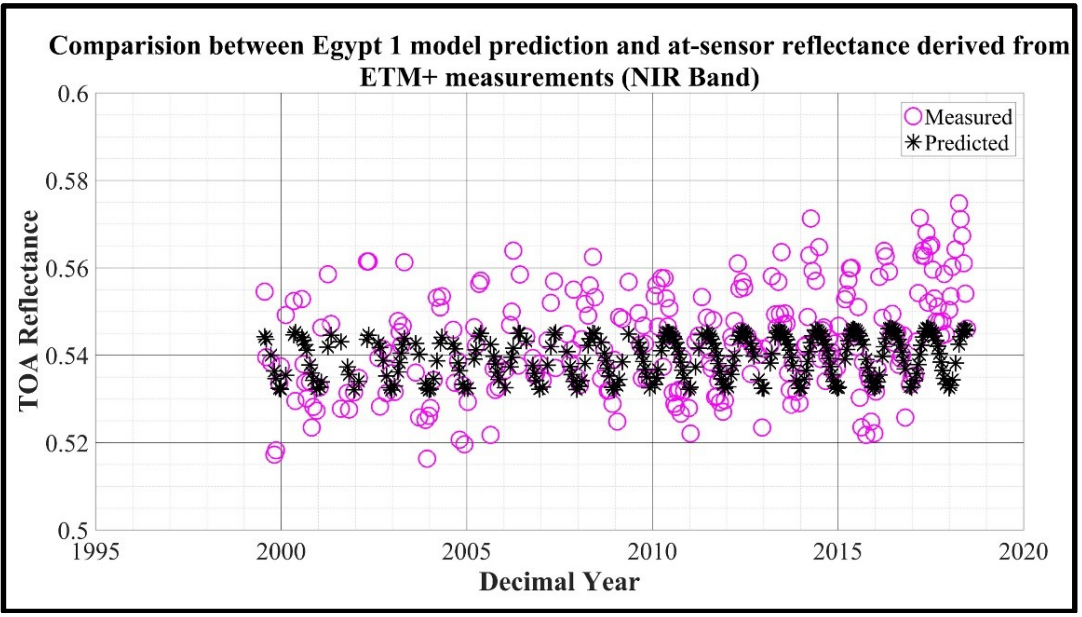

Figure 9. L7 ETM+ observations of Egypt 1(circle) and model prediction (asterisk).

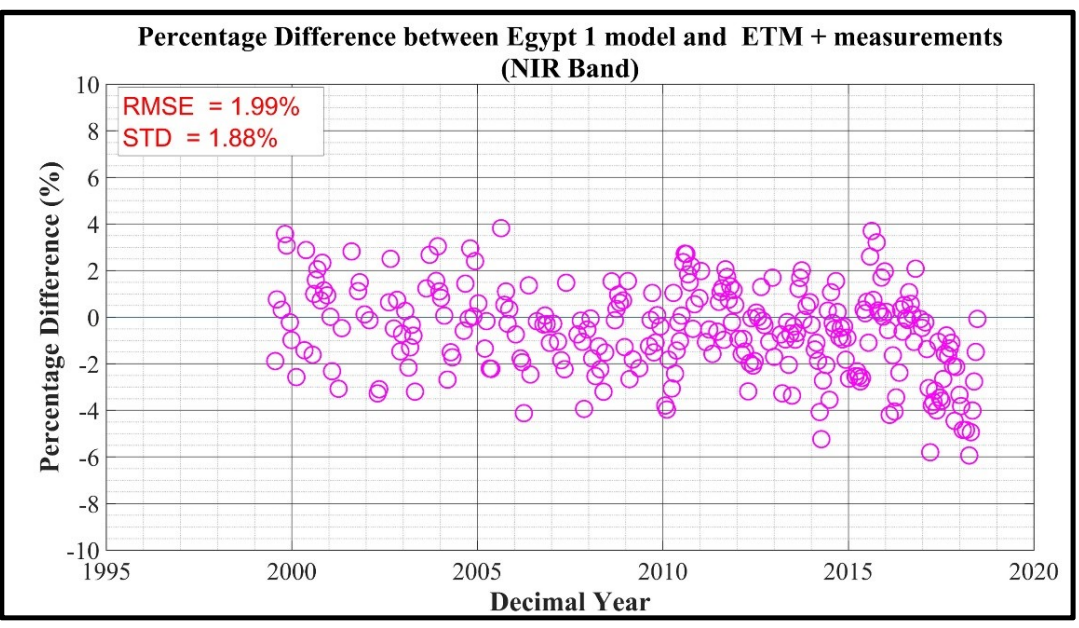

Figure 10. Percentage difference between L7 ETM+ observations and model predictions.

Figure 11 compares the model-predicted and measured TOA reflectances in the L8 OLI NIR band for Egypt 1 from 2013 to 2018. The predicted reflectances generally track the measured reflectances quite well with respect to overall seasonal variability. For data acquired early in the L8 OLI lifetime, the model predicts reflectance level precisely. For data acquired between late 2015 and 2016, the model predicts a slightly higher reflectance level, then predicts reflectance accurately from 2017 onwards. Figure 12 shows the corresponding percentage differences. The estimated model accuracy and precision of approximately $0.88 \%$ and $0.87 \%$, respectively, are well within Libya 4 's estimated values. 


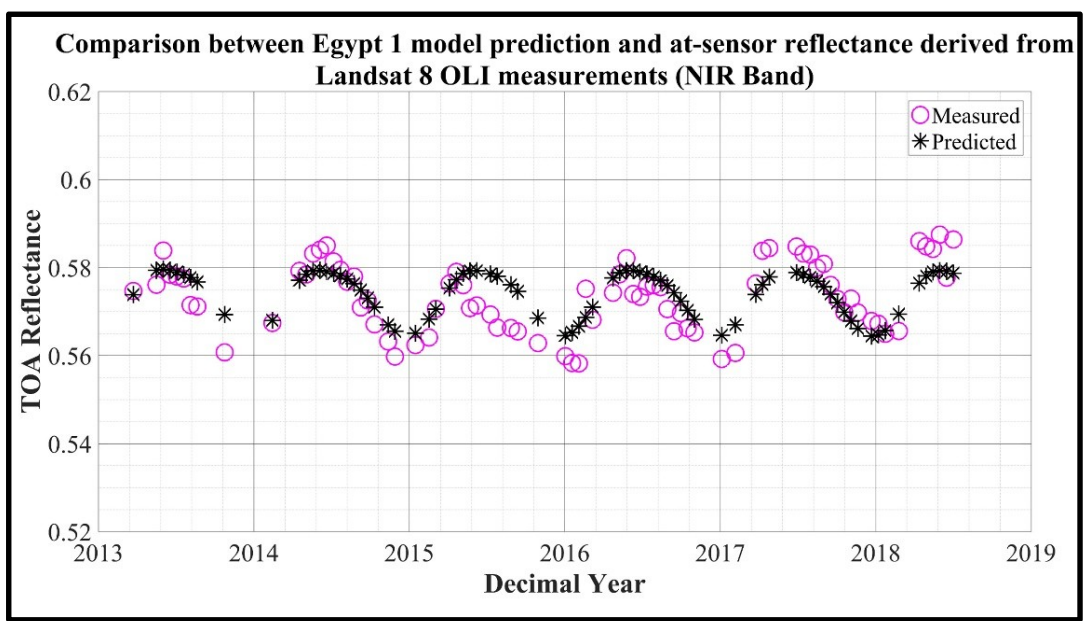

Figure 11. L8 OLI observations of Egypt 1(circle) and model prediction (asterisk).

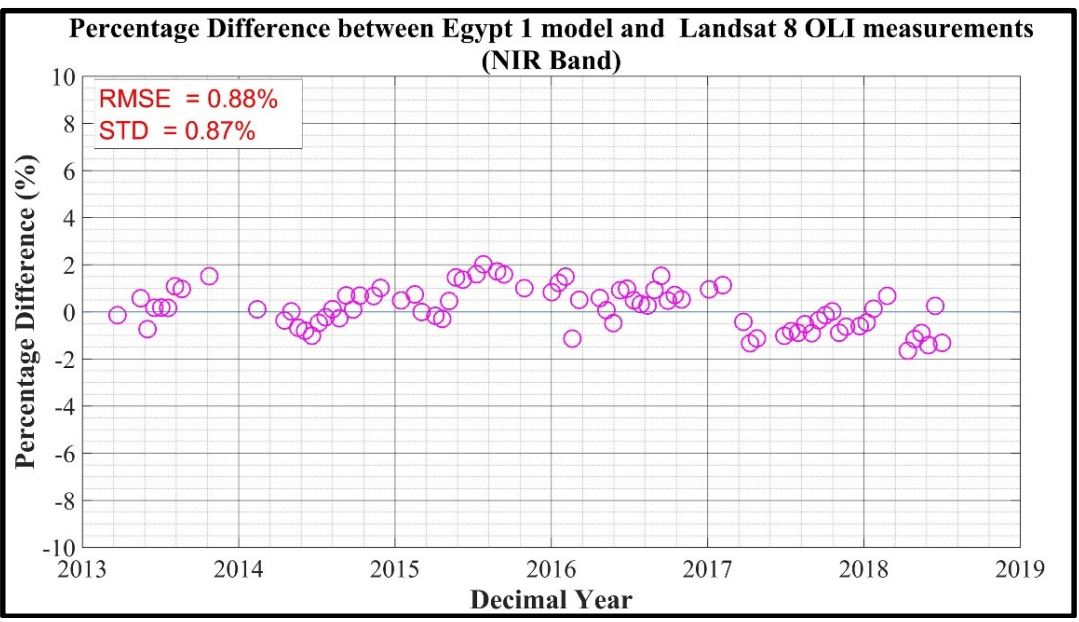

Figure 12. Percentage difference between L8 OLI observations and model predictions.

Figure 13 compares the model-predicted and measured TOA reflectances in the S2A-MSI NIR band for Egypt 1 from 2015 to 2018. As with the L7 ETM+ and L8 OLI, the predicted reflectances generally track the measured reflectances quite well with respect to overall seasonal variability. For data acquired early in the lifetime, the model predicts slightly higher reflectance; for data acquired from 2016 on, the model consistently predicts lower reflectance levels, with more deviation from the measured reflectances observed from approximately mid-2017 on. This may very well be due to both the relatively small amount of available data early in the lifetime, and also to the successive calibration changes in the final image products. Figure 14 shows the corresponding percentage differences; the estimated model accuracy and precision of approximately $1.78 \%$ and $1.22 \%$, respectively, are well within Libya 4 's estimated values.

Figure 15 compares the model-predicted and measured TOA reflectances in the S2B MSI NIR band for Egypt 1 from 2017 to 2018 . Again, the predicted reflectances generally track the measured reflectances quite well with respect to overall seasonal variability. The model consistently predicts a lower reflectance level than the measured values; the degree of deviation appears to be greater in 2018, but is less than the deviation observed for the S2A MSI. This should perhaps be expected, given that even fewer data are available for this sensor than the S2A MSI. Figure 16 shows the corresponding percentage differences; the estimated model accuracy and precision of approximately $1.37 \%$ and $0.58 \%$, respectively, are well within Libya 4's estimated values. 


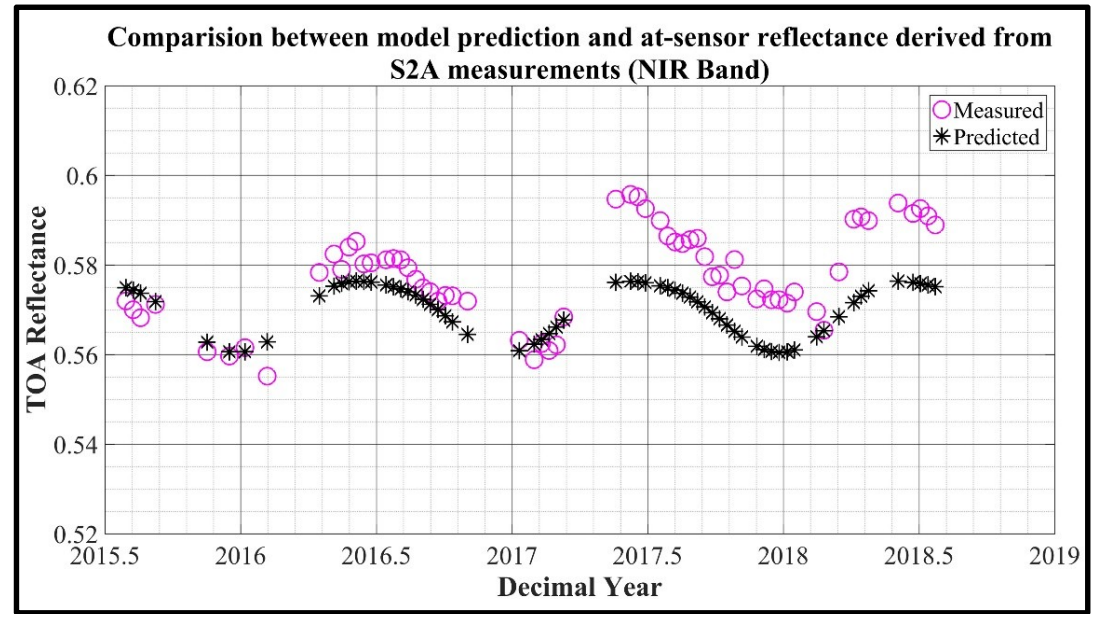

Figure 13. S2A MSI observation of Egypt 1(circle) and model prediction (asterisk).

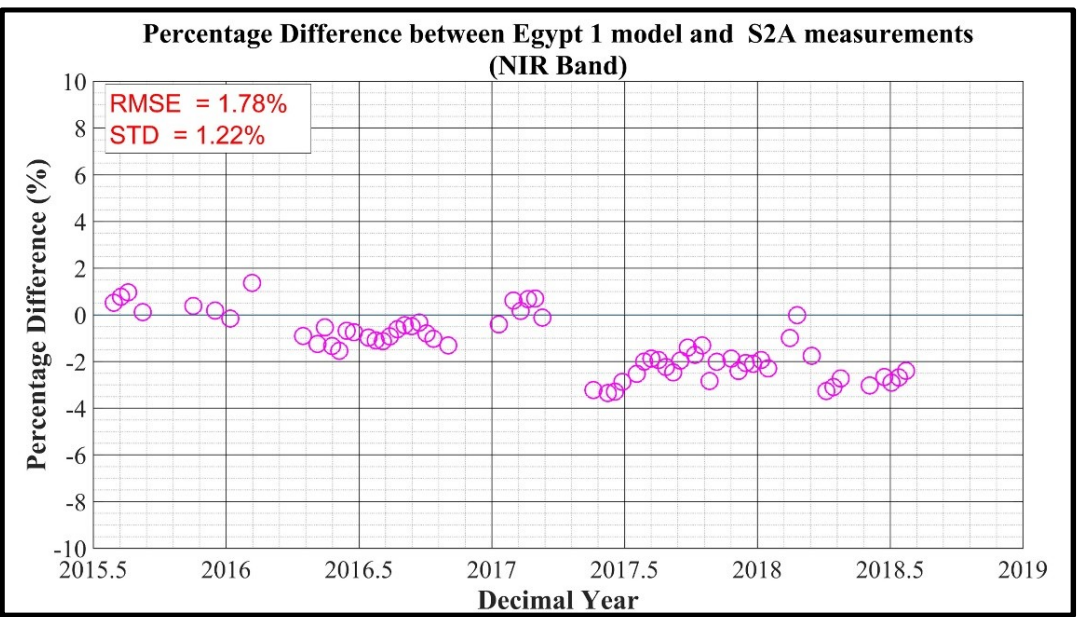

Figure 14. Percentage Difference between S2A MSI measurements and model predictions.

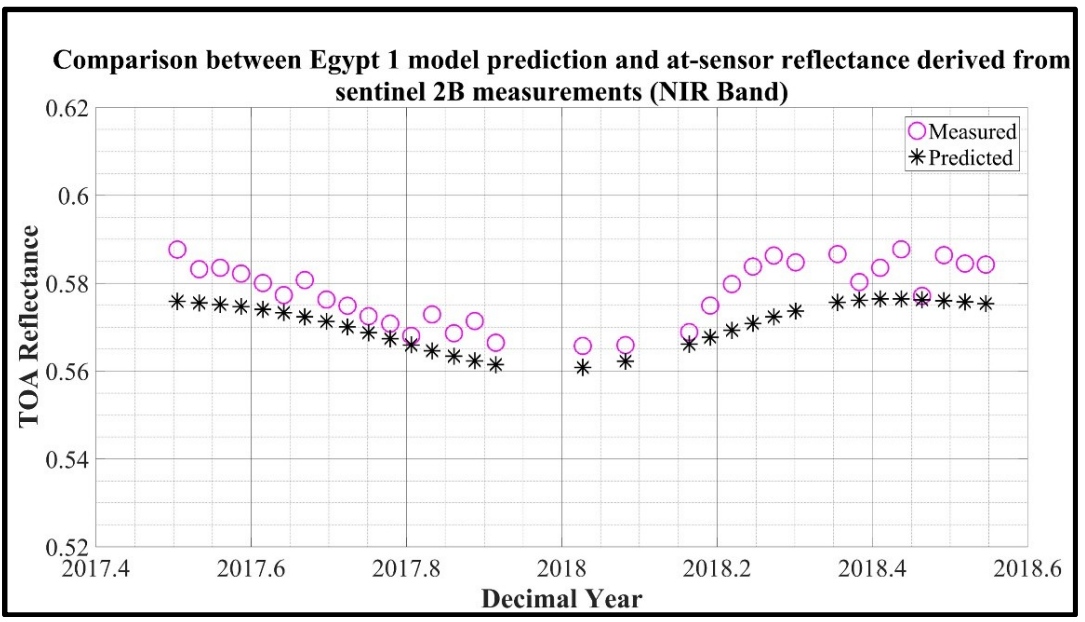

Figure 15. S2B MSI observation of Egypt 1(circle) and model prediction (asterisk).

Figures 17 and 18, respectively, show the accuracy and precision, by band, for all sensors estimated for the Egypt 1 model. With the exception of the L7 ETM+ SWIR-1 band accuracy of approximately $3.1 \%$ and the L8 OLI and S2A MSI Green band accuracies over $2.5 \%$, all sensors demonstrate accuracy of $2.5 \%$ or better. The estimated precision of the model is within $2 \%$ for all sensor across all bands, 
except SWIR-2 band of L7 ETM+. In general, the precision of the model for this site is approximately $2 \%$ or better. This result shows an absolute calibration model with an accuracy of $3 \%$ is possible using Egypt 1 .

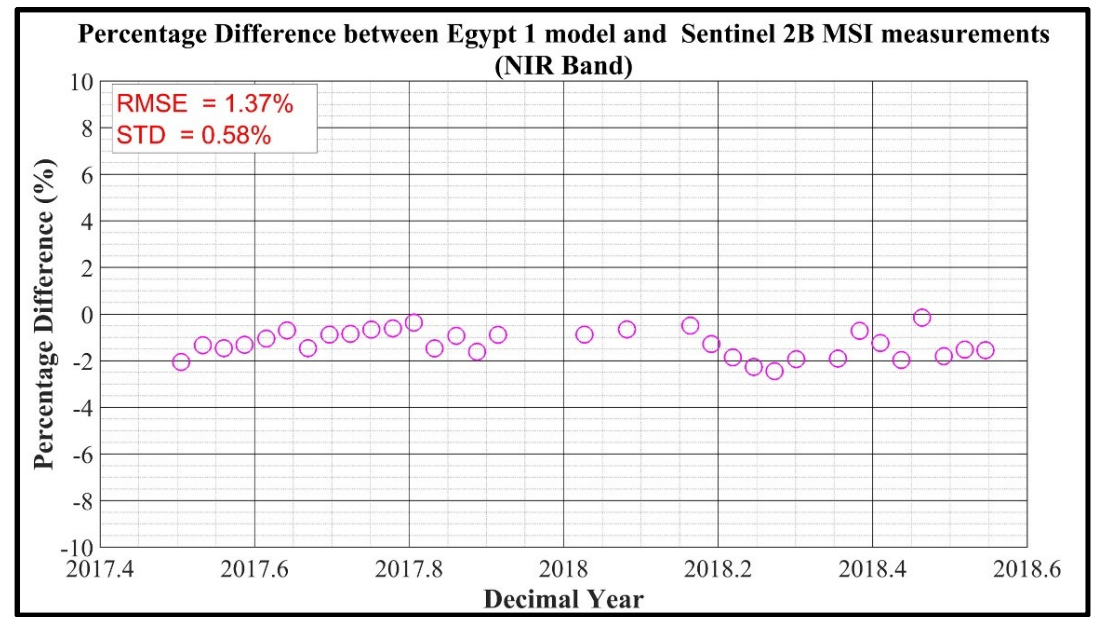

Figure 16. Percentage Difference between S2B MSI measurements and model predictions.

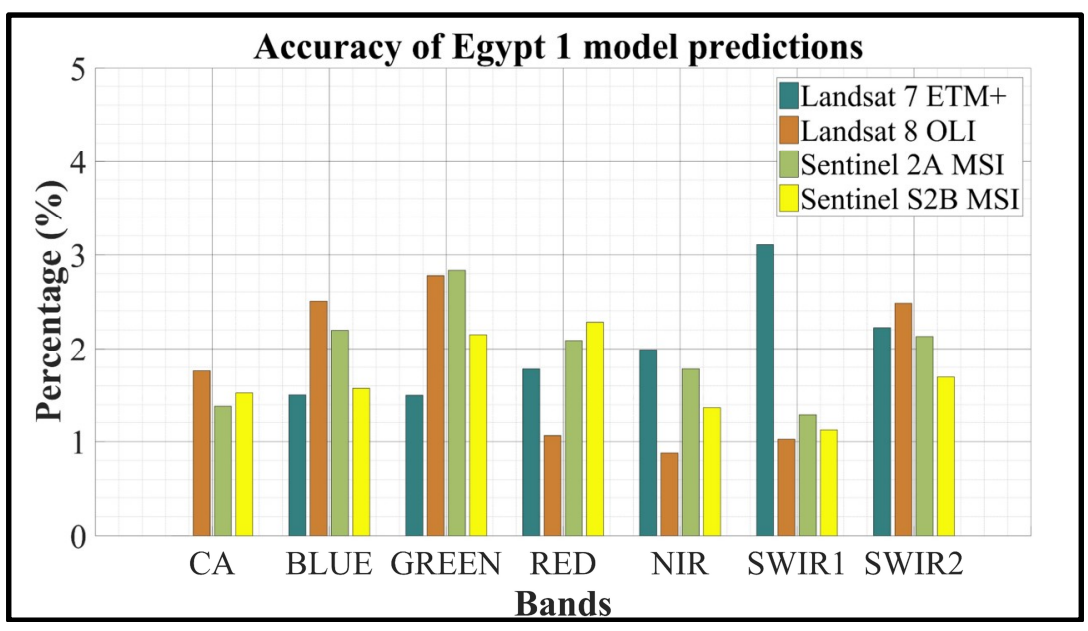

Figure 17. Estimate of accuracy between sensor observation and Egypt1 model prediction.

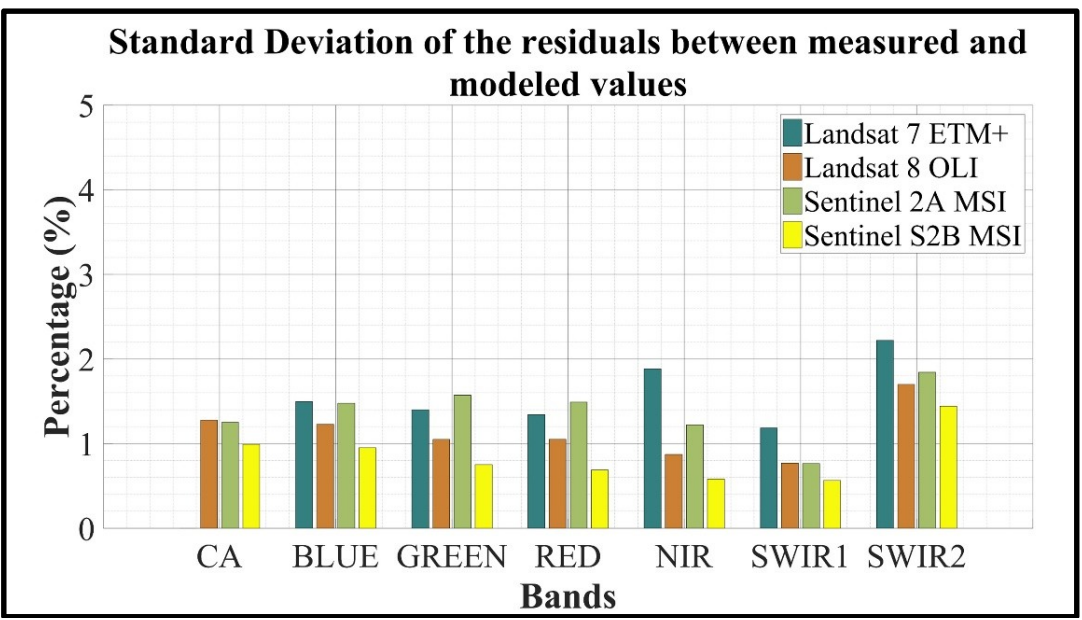

Figure 18. Estimate of precision of the Egypt 1 model for the selected sensor. 
Similar comparisons were performed for the models generated for the remaining PICS. Tables 7 and 8 give the Libya 1 absolute calibration model accuracy and precision, respectively. Overall accuracy of approximately 3\% can be expected, except in the L7 ETM+ Blue band, where the estimated accuracy is approximately $3.8 \%$. The estimated precision of the model is within $2 \%$ for all sensors across all bands.

Table 7. Accuracy between measured and Libya 1 simulated values.

\begin{tabular}{cccccccc}
\hline Sensors & CA & Blue & Green & Red & NIR & SWIR-1 & SWIR-2 \\
\hline L7 ETM + (\%) & NA & 3.77 & 2.96 & 1.03 & 2.93 & 0.95 & 2.82 \\
L8 OLI (\%) & 2.23 & 2.53 & 1.13 & 2.12 & 1.51 & 1.00 & 1.25 \\
S2A MSI (\%) & 1.47 & 1.48 & 1.55 & 2.42 & 1.46 & 0.57 & 1.66 \\
S2B MSI (\%) & 1.37 & 1.95 & 1.89 & 2.18 & 0.97 & 1.21 & 1.54 \\
\hline
\end{tabular}

Table 8. Libya 1 random error (precision) between measured and simulated values.

\begin{tabular}{cccccccc}
\hline Sensors & CA & Blue & Green & Red & NIR & SWIR-1 & SWIR-2 \\
\hline L7 ETM + (\%) & NA & 1.90 & 1.15 & 0.54 & 1.33 & 0.89 & 1.35 \\
L8 OLI (\%) & 1.76 & 1.76 & 1.08 & 0.60 & 0.53 & 0.83 & 1.12 \\
S2A MSI (\%) & 1.45 & 1.37 & 0.92 & 0.37 & 0.28 & 0.46 & 1.62 \\
S2B MSI (\%) & 1.40 & 1.50 & 1.02 & 0.44 & 0.29 & 0.60 & 0.82 \\
\hline
\end{tabular}

For Sudan 1, overall accuracy of approximately 3\% can be expected across most bands for all sensors. Unlike Egypt 1, the exception is the L7 ETM+ SWIR-1 band, where the expected accuracy is approximately $3.8 \%$. The expected precision for the model across all bands for all sensors is similar to Egypt 1, at around 2\%. Tables 9 and 10 provide the calculated accuracy and precision for all bands.

Table 9. Accuracy between measured and Sudan 1 simulated values.

\begin{tabular}{cccccccc}
\hline Sensors & CA & Blue & Green & Red & NIR & SWIR-1 & SWIR-2 \\
\hline L7 ETM + (\%) & NA & 2.85 & 2.14 & 2.13 & 1.98 & 3.77 & 2.04 \\
L8 OLI (\%) & 2.21 & 1.51 & 1.25 & 1.33 & 1.02 & 1.16 & 2.17 \\
S2A MSI (\%) & 1.52 & 2.67 & 1.86 & 0.92 & 0.69 & 0.56 & 2.18 \\
S2B MSI (\%) & 1.96 & 3.00 & 2.44 & 0.82 & 1.17 & 0.87 & 1.61 \\
\hline
\end{tabular}

Table 10. Sudan 1 random error (precision) between measured and simulated values.

\begin{tabular}{cccccccc}
\hline Sensors & CA & Blue & Green & Red & NIR & SWIR-1 & SWIR-2 \\
\hline L7 ETM + (\%) & NA & 1.72 & 1.21 & 1.18 & 1.81 & 1.11 & 2.04 \\
L8 OLI (\%) & 1.47 & 1.45 & 1.25 & 1.31 & 1.02 & 1.17 & 2.14 \\
S2A MSI (\%) & 1.34 & 1.19 & 0.80 & 0.87 & 0.66 & 0.50 & 1.97 \\
S2B MSI (\%) & 1.34 & 1.19 & 0.80 & 0.87 & 0.66 & 0.50 & 1.97 \\
\hline
\end{tabular}

For Niger 1, accuracies worse than 3\% can be expected in the Blue and Green bands for all sensors except the L7 ETM+. In its current state, the Niger 1 model could predict reflectance to within approximately $7 \%$ in the Blue and Green bands. The expected precision across all bands for all sensors is within $2 \%$. Tables 11 and 12 give accuracy and random errors obtained for each band.

Table 11. Accuracy between measured and Niger 1 simulated values.

\begin{tabular}{cccccccc}
\hline Sensors & CA & Blue & Green & Red & NIR & SWIR-1 & SWIR-2 \\
\hline L7 ETM + (\%) & NA & 1.90 & 0.99 & 0.76 & 1.98 & 1.31 & 1.79 \\
L8 OLI (\%) & 1.70 & 4.67 & 5.13 & 1.97 & 0.50 & 1.28 & 1.72 \\
S2A MSI (\%) & 2.50 & 4.63 & 5.66 & 1.18 & 0.53 & 0.76 & 2.27 \\
S2B MSI (\%) & 1.37 & 5.06 & 6.77 & 2.55 & 1.20 & 1.45 & 2.66 \\
\hline
\end{tabular}


Table 12. Niger 1 random error (precision) between measured and simulated values.

\begin{tabular}{cccccccc}
\hline Sensors & CA & Blue & Green & Red & NIR & SWIR-1 & SWIR-2 \\
\hline L7 ETM + (\%) & NA & 1.80 & 0.82 & 0.56 & 1.28 & 1.12 & 1.64 \\
L8 OLI (\%) & 1.67 & 1.56 & 0.75 & 0.58 & 0.43 & 0.87 & 1.70 \\
S2A MSI (\%) & 1.49 & 1.25 & 0.61 & 0.55 & 0.43 & 0.69 & 1.63 \\
S2B MSI (\%) & 0.28 & 0.29 & 0.43 & 0.65 & 0.59 & 0.92 & 1.60 \\
\hline
\end{tabular}

For Niger 2, accuracies worse than 3\% can be expected across all bands for all sensors except L8 OLI. In its current form, the Niger 2 model could predict reflectance to an accuracy of approximately $7 \%$ in the SWIR-2 band. The expected precision of the model is within $2.5 \%$ for all sensors across all bands except the S2A MSI CA and Blue bands. As stated earlier, this is most likely due to the extremely limited amount of Hyperion data available before 2012 and the steadily decreasing reliability of the post-2012 data due to the changes in its orbit. Tables 13 and 14 present the Niger 2 absolute calibration model accuracy and precision for all bands.

Table 13. Accuracy between measured and Niger 2 simulated values.

\begin{tabular}{cccccccc}
\hline Sensors & CA & Blue & Green & Red & NIR & SWIR-1 & SWIR-2 \\
\hline L7 ETM + (\%) & NA & 4.25 & 4.55 & 2.57 & 3.97 & 1.57 & 7.58 \\
L8 OLI (\%) & 2.19 & 1.25 & 1.38 & 1.82 & 2.09 & 2.53 & 3.71 \\
S2A MSI (\%) & 6.69 & 3.81 & 3.41 & 4.57 & 4.34 & 3.35 & 6.54 \\
S2B MSI (\%) & 3.60 & 2.57 & 1.11 & 3.81 & 3.40 & 3.30 & 7.79 \\
\hline
\end{tabular}

Table 14. Niger 2 random error (precision) between measured and simulated values.

\begin{tabular}{cccccccc}
\hline Sensors & CA & Blue & Green & Red & NIR & SWIR-1 & SWIR-2 \\
\hline L7 ETM + (\%) & NA & 1.67 & 1.35 & 1.45 & 2.06 & 1.54 & 2.49 \\
L8 OLI (\%) & 0.51 & 0.54 & 0.41 & 0.53 & 0.65 & 0.80 & 1.21 \\
S2A MSI (\%) & 3.83 & 3.83 & 2.43 & 1.78 & 1.60 & 1.23 & 2.37 \\
S2B MSI (\%) & 1.39 & 1.41 & 1.06 & 1.09 & 1.08 & 1.08 & 2.14 \\
\hline
\end{tabular}

Results obtained for Egypt 1, Libya 1 and Sudan 1 are generally consistent with the Libya 4 results presented by Mishra et al., and show excellent potential for use in PICS-based absolute calibration. As mentioned earlier, the new models for these sites do not account for atmospheric effects, and the BRDF models consider only solar and sensor zenith angles constrained to $\pm 7.5^{\circ}$ and $\pm 20^{\circ}$ departures, respectively, from nadir. Thus, the precision and accuracy of these models could be improved by including a BRDF model based on the physical properties of the surface.

\subsection{Uncertainty Analysis}

\subsection{1. k-scale Factor Uncertainty}

Due to differences in sensor revisit times between Terra MODIS and Hyperion, and the resulting differences in sensor viewing geometry, solar illumination, and atmospheric conditions, the use of near-coincident image pairs will introduce uncertainty in the estimated k-scale factor for each model. The uncertainty in the k-scale factor for each site's model was estimated as the ratio of the standard deviation in the k-scale factors for each band to the overall mean; the estimated uncertainties ranged between approximately $0.1 \%$ to $8.7 \%$. The largest uncertainties were observed for the CA, Blue, and SWIR-2 bands in the Niger 2 model. This may be due to the relaxation of requirements used to identify near-coincident image pairs to account for the reduced availability of reliable Hyperion image data. 


\subsubsection{Solar and Sensor View Zenith Uncertainty}

The minimum uncertainty in estimating the solar zenith angle is approximately $\pm 0.01^{\circ}$. For solar angles between $20^{\circ}$ and $60^{\circ}$, the uncertainties ranged from approximately $0.1 \%$ to $0.3 \%$ respectively [32] The model works reasonably well if the sensor viewing angles are restricted to within $\pm 20^{\circ}$ degrees of nadir. The uncertainty of the VZA for $\pm 20^{\circ}$ from nadir is lower than $0.01^{\circ}$.

\subsubsection{BRDF Model Coefficient Uncertainty}

As discussed in the Methods section, BRDF effects in the models were introduced using two zenith angles: the solar zenith angle, modeled as a linear function of solar zenith angle (where the intercept was used to normalize the reflectance to a $30^{\circ}$ angle); and the view zenith angle, modeled as a quadratic function of sensor view zenith angle (using just the linear and quadratic terms). The uncertainty of each BRDF model coefficient was estimated for each band as the difference between the predicted coefficient value and its associated upper $95 \%$ confidence interval bound. The coefficient uncertainties were used in Equation (7) to estimate the total BRDF model coefficient uncertainty.

\subsubsection{Hyperion Spectral Uncertainty}

An additional source of uncertainty comes from the hyperspectral profile of the PICS itself. As the hyperspectral profile of the PICS was derived from near-coincident image data, differences in solar illumination, sensor viewing geometry, and atmospheric characteristics result in differences in the hyperspectral reflectance profile. For the data used in this analysis, the estimated uncertainties in the hyperspectral profile data (i.e., the ratio of the standard deviation to the mean) are between approximately 1.3 and $4.1 \%$, with greater estimated uncertainty in the shorter wavelength bands.

\subsubsection{Total Estimated Uncertainty}

Table 15 shows the estimated uncertainties for each model parameter. Under the assumption that all model variables are uncorrelated, Equation (7) was used to estimate the overall model uncertainty. Table 16 summarizes the uncertainties for each band for all the five PICS sites. The general uncertainty ranges between approximately $1.07 \%$ and $9.35 \%$. Niger 2 showed uncertainties of more than $7 \%$ for the CA, Blue and SWIR-2 bands.

Table 15. Absolute calibration model parameter uncertainties.

\begin{tabular}{ccc}
\hline Uncertainty Source & Uncertainty (\%) & Remarks \\
\hline k-scale factor & $0.1 \%-8.7 \%$ & All bands and all five PICS \\
Hyperion spectra & $1.3 \%-4.8 \%$ & All bands and all five PICS \\
SZA $\left[20^{\circ}-60^{\circ}\right]$ & $0.1 \%$ & All bands and all five PICS \\
VZA $\left[ \pm 20^{\circ}\right.$ of nadir $]$ & $0.5 \%$ & All bands and all five PICS \\
\hline
\end{tabular}

Table 16. Total uncertainties for each PICS absolute calibration model.

\begin{tabular}{cccccc}
\hline Bands & Egypt 1 & Libya 1 & Niger 1 & Niger 2 & Sudan 1 \\
\hline CA (\%) & 3.86 & 3.88 & 5.63 & 9.08 & 5.55 \\
Blue (\%) & 3.82 & 4.02 & 5.49 & 9.35 & 4.98 \\
Green (\%) & 3.62 & 2.73 & 5.03 & 4.08 & 4.88 \\
Red (\%) & 2.91 & 1.07 & 3.99 & 1.88 & 4.08 \\
NIR (\%) & 2.60 & 1.55 & 3.81 & 1.74 & 3.69 \\
SWIR-1 (\%) & 1.85 & 1.35 & 4.06 & 3.39 & 2.85 \\
SWIR-2 (\%) & 2.71 & 3.72 & 5.78 & 7.50 & 4.00 \\
\hline
\end{tabular}




\section{Conclusions}

Sahara Desert PICS such as Egypt 1, Libya 1, Niger 1, Niger 2, and Sudan 1 have proven to be stable and reliable enough for use in sensor stability assessment and calibration. This article explores the development and validation of empirical absolute calibration models for these PICS and considers whether they can be used for absolute radiometric calibration.

For this work, data from the Terra MODIS and EO-1 Hyperion sensors were used to develop the absolute calibration models. MODIS served as a well-calibrated reference radiometer, and Hyperion image data were used to obtain spectral information for each PICS. As much as possible, image data from both sensors were used that intersected with standard SDSU ROIs for these sites, which are located within "optimal" regions exhibiting no more than $3 \%$ temporal, spatial, and spectral stability.

Prior model development focused on Libya 4, ultimately achieving an accuracy of approximately $3 \%$ and precision of $2 \%$ for this site. This work extends the Libya 4 model to five additional PICS and includes explicit consideration of associated uncertainties. The models have been validated with the L7 ETM+, L8 OLI, and Sentinel 2A/2B MSI. Results showed that the models for Egypt 1, Libya 1 and Sudan 1 could predict TOA reflectance with $3 \%$ or better accuracy and $2 \%$ or better precision, comparable to Libya 4 . In its current state, the Niger 1 model could predict reflectance to within approximately $7 \%$ in the Blue and Green bands for all sensors, except for the L7 ETM+. The Niger 2 model was able to predict reflectance to an accuracy of approximately $7 \%$ in the SWIR-2 band for all sensors except L8 OLI. In addition, lower accuracy was observed in other bands for all sensors except L8 OLI. The significantly worse performance of the Niger models is most likely due to an insufficient amount of reliable Hyperion data over these sites. In general, given a sufficient quantity of good quality hyperspectral image data for a PICS, an absolute calibration model could be developed with this approach to an accuracy and precision that matches or even exceeds the Libya 4 model.

A detailed analysis has been performed to estimate the total uncertainty for each model. The total uncertainty of the models ranges from approximately $1.07 \%$ to $9.35 \%$. Overall, the Egypt 1 model exhibits an uncertainty of approximately $4 \%$ or less in all bands. The Libya 1 and Sudan 1 models exhibit uncertainties of approximately $5 \%$ or less except CA band of Sudan 1 . The Niger 1 and Niger 2 models exhibit much greater uncertainties, primarily due to the lack of image data to generate a reasonable hyperspectral profile. Based on these results, Egypt 1, Libya 1, and Sudan 1 would be good candidate PICS for further research into model development and validation, and for use in optical sensor calibration.

Nevertheless, improvements in model accuracy and precision and reductions in uncertainty are possible. Low accuracy of the models is most likely driven by calibration differences between Terra MODIS and the other sensors. Random errors are most likely due to atmospheric conditions at the sensor overpass time. The models as currently implemented only consider the solar and sensor view zenith angles for BRDF modeling; development of a BRDF model from first principles based on surface properties and spectral profiles could lead to a more robust correction.

Author Contributions: Conceptualization, B.R., M.K. and D.H.; methodology, B.R. and M.K.; software, B.R.; validation, B.R.; formal analysis, B.R.; investigation, B.R.; resources, M.K., A.A. and X.X.; writing—original draft preparation, B.R.; writing_-review and editing, M.K. and D.H; visualization, B.R.; supervision, M.K.

Funding: This research was funded by NASA (grant number NNX15AP36A) and USGS EROS (grant number G14AC00370).

Acknowledgments: Many thanks to Tim Ruggles for providing constant support and invaluable suggestions on writing and editing the paperwork. We are grateful to members from USGS EROS, MCST team for sharing the Landsat, Hyperion and Terra MODIS data that are the basis of this work. At last, we enthusiastically acknowledge all the reviewers for their invaluable comments and suggestion for improving the manuscript.

Conflicts of Interest: The authors declare no conflict of interest. 


\section{References}

1. Cosnefroy, H.; Leroy, M.; Briottet, X. Selection and characterization of Saharan and Arabian desert sites for the calibration of optical satellite sensors. Remote. Sens. Environ. 1996, 58, 101-114. [CrossRef]

2. EROS. Committee on Earth Observation Satellites (CEOS) Legacy - Calibration/Validation Test Sites. Available online: https://www.usgs.gov/centers/eros/science/usgs-eros-archive-committee-earthobservation-satellites-ceos-legacy?qt-science_center_objects=0\#qt-science_center_objects (accessed on 8 May 2019).

3. Helder, D.L.; Basnet, B.; Morstad, D.L. Optimized identification of worldwide radiometric pseudo-invariant calibration sites. Can. J. Remote. Sens. 2010, 36, 527-539. [CrossRef]

4. Mishra, N.; Helder, D.; Angal, A.; Choi, J.; Xiong, X. Absolute calibration of optical satellite sensors using Libya 4 pseudo invariant calibration site. Remote. Sens. 2014, 6, 1327-1346. [CrossRef]

5. Pinto, C.; Ponzoni, F.; Castro, R.; Leigh, L.; Mishra, N.; Aaron, D.; Helder, D. First in-flight radiometric calibration of MUX and WFI on-board CBERS-4. Remote. Sens. 2016, 8, 405. [CrossRef]

6. Mishra, N.; Helder, D.; Barsi, J.; Markham, B. Continuous calibration improvement in solar reflective bands: Landsat 5 through Landsat 8. Remote. Sens. Environ. 2016, 185, 7-15. [CrossRef] [PubMed]

7. Mishra, N.; Haque, M.O.; Leigh, L.; Aaron, D.; Helder, D.; Markham, B. Radiometric cross calibration of Landsat 8 operational land imager (OLI) and Landsat 7 enhanced thematic mapper plus (ETM+). Remote. Sens. 2014, 6, 12619-12638. [CrossRef]

8. Bhatt, R.; Doelling, D.R.; Morstad, D.; Scarino, B.R.; Gopalan, A. Desert-based absolute calibration of successive geostationary visible sensors using a daily exoatmospheric radiance model. IEEE Trans. Geosci. Remote. Sens. 2014, 52, 3670-3682. [CrossRef]

9. Vuppula, H. Normalization of Pseudo-invariant Calibration Sites for Increasing the Temporal Resolution and Long-term Trending. Master's Theses, South Dakota State University, South Dakota, SD, USA, 30 July 2017.

10. Helder, D.; Thome, K.J.; Mishra, N.; Chander, G.; Xiong, X.; Angal, A.; Choi, T. Absolute radiometric calibration of Landsat using a pseudo invariant calibration site. IEEE Trans. Geosci. Remote. Sens. 2013, 51, 1360-1369. [CrossRef]

11. Govaerts, Y.M.; Clerici, M. Evaluation of radiative transfer simulations over bright desert calibration sites. IEEE Trans. Geosci. Remote. Sens. 2004, 42, 176-187. [CrossRef]

12. Govaerts, Y.; Sterckx, S.; Adriaensen, S. Optical sensor calibration using simulated radiances over desert sites. In Proceedings of the 2012 IEEE International Geoscience and Remote Sensing Symposium, Munich, Germany, 22-27 July 2012; IEEE: Piscataway, NJ, USA, 2012; pp. 6932-6935.

13. Bouvet, M. Radiometric comparison of multispectral imagers over a pseudo-invariant calibration site using a reference radiometric model. Remote. Sens. Environ. 2014, 140, 141-154. [CrossRef]

14. Xiong, X.; Barnes, W. An overview of MODIS radiometric calibration and characterization. Adv. Atmos. Sci. 2006, 23, 69-79. [CrossRef]

15. Xiong, X.; Sun, J.; Barnes, W.; Salomonson, V.; Esposito, J.; Erives, H.; Guenther, B. Multiyear on-orbit calibration and performance of Terra MODIS reflective solar bands. IEEE Trans. Geosci. Remote. Sens. 2007, 45, 879-889. [CrossRef]

16. Sun, J.-Q.; Xiong, X.; Barnes, W.L.; Guenther, B. MODIS reflective solar bands on-orbit lunar calibration. IEEE Trans. Geosci. Remote. Sens. 2007, 45, 2383-2393. [CrossRef]

17. Ungar, S.G.; Pearlman, J.S.; Mendenhall, J.A.; Reuter, D. Overview of the earth observing one (EO-1) mission. IEEE Trans. Geosci. Remote. Sens. 2003, 41, 1149-1159. [CrossRef]

18. Pearlman, J.S.; Barry, P.S.; Segal, C.C.; Shepanski, J.; Beiso, D.; Carman, S.L. Hyperion, a space-based imaging spectrometer. IEEE Trans. Geosci. Remote. Sens. 2003, 41, 1160-1173. [CrossRef]

19. Middleton, E.M.; Ungar, S.G.; Mandl, D.J.; Ong, L.; Frye, S.W.; Campbell, P.E.; Landis, D.R.; Young, J.P.; Pollack, N.H. The earth observing one (EO-1) satellite mission: Over a decade in space. EEE J. Sel. Top. Appl. Earth Obs. Remote. Sens. 2013, 6, 243-256. [CrossRef]

20. McCorkel, J.; Thome, K.; Ong, L. Vicarious calibration of EO-1 Hyperion. IEEE J. Sel. Top. Appl. Earth Obs. Remote. Sens. 2013, 6, 400-407. [CrossRef]

21. Campbell, P.K.E.; Middleton, E.M.; Thome, K.J.; Kokaly, R.F.; Huemmrich, K.F.; Lagomasino, D.; Novick, K.A.; Brunsell, N.A. EO-1 hyperion reflectance time series at calibration and validation sites: Stability and sensitivity to seasonal dynamics. IEEE J. Sel. Top. Appl. Earth Obs. Remote. Sens. 2013, 6, 276-290. [CrossRef] 
22. Farhad, M.M. Cross Calibration and Validation of Landsat 8 OLI and Sentinel 2A MSI. Master's Theses, South Dakota State University, South Dakota, SD, USA, 18 April 2018.

23. Hapke, B. Bidirectional reflectance spectroscopy: 1. Theory. J. Geophys. Res.: Solid Earth 1981, 86, 3039-3054. [CrossRef]

24. Snyder, W.C.; Wan, Z. BRDF models to predict spectral reflectance and emissivity in the thermal infrared. IEEE Trans. Geosci. Remote. Sens. 1998, 36, 214-225. [CrossRef]

25. Lucht, W.; Schaaf, C.B.; Strahler, A.H. An algorithm for the retrieval of albedo from space using semiempirical BRDF models. IEEE Trans. Geosci. Remote. Sens. 2000, 38, 977-998. [CrossRef]

26. Shrestha, M. Bidirectional Distribution Reflectance Function of Algodones Dunes. Master's Theses, South Dakota State University, South Dakota, SD, USA, 25 December 2016.

27. Barsi, J.A.; Alhammoud, B.; Czapla-Myers, J.; Gascon, F.; Haque, M.O.; Kaewmanee, M.; Leigh, L.; Markham, B.L. Sentinel-2A MSI and Landsat-8 OLI radiometric cross comparison over desert sites. Eur. J. Remote. Sens. 2018, 51, 822-837. [CrossRef]

28. Helder, D.; Kaewmanee, M.; Farhad, M.M. Landsat 8 OLI and Sentinel 2 Data Interoperability: Looking from the Calibration Perspective. South Dakota State University: Earth Resources Observation and Science (EROS) Center CalVal Center of Excellence (ECCOE). 2017. Available online: https://calval.cr.usgs.gov/apps/ sites/default/files/jacie/DHelderJACIETalk2017Final.pdf (accessed on 8 May 2019).

29. Bujang, M.A.; Baharum, N. Sample size guideline for correlation analysis. World J. Soc. Sci. Res. 2016, 3, 39-41. [CrossRef]

30. ENV13005, N. Guide to the Expression of Uncertainty in Measurement; AFNOR: Paris, France, 1999; pp. 18-20. Available online: https://www.bipm.org/utils/common/documents/jcgm/JCGM_100_2008_E.pdf (accessed on 8 May 2019).

31. Markham, B.L.; Thome, K.J.; Barsi, J.A.; Kaita, E.; Helder, D.L.; Barker, J.L.; Scaramuzza, P.L. Landsat-7 ETM+ on-orbit reflective-band radiometric stability and absolute calibration. IEEE Trans. Geosci. Remote. Sens. 2004, 42, 2810-2820. [CrossRef]

32. Ibrahim, R.; Afshin, A. Solar Position Algorithm for Solar Radiation Applications. Solar Energy 2004, 76, 577-589. [CrossRef] 